\title{
CONTRAST-ENHANCED MAGNETIC RESONANCE IMAGING OF LUNG CELL CULTURES
}

\author{
ZUZANNA BOBER ${ }^{1}$, KATARZYNA POGODA², DAVID AEBISHER ${ }^{1}$, \\ JACEK TABARKIEWICZ ${ }^{2}$ and DOROTA BARTUSIK-AEBISHER ${ }^{3 *}$
}

\author{
'Department of Photomedicine and Physical Chemistry, \\ ${ }^{2}$ Centre for Innovative Research in Medical and Natural Sciences, \\ ${ }^{3}$ Department of Biochemistry and General Chemistry, \\ Medical College of The University of Rzeszów, Kopisto 2A, 35-315 Rzeszów, Poland
}

\begin{abstract}
Lung cancer is one of the most common types of cancer diagnosed, and the development of methods to image diseased lung tissue by MRI is of utmost importance. Contrast-Enhanced Magnetic Resonance Imaging (CE-MRI) was used to noninvasively evaluate spin-spin relaxation time, $\mathrm{T}_{1}$, of lung cell cultures infused with various clinical gadolinium-based contrast media for imaging. In this study we used a clinical 1.5 Tesla scanner and the contrast agents: Omniscan, MultiHance, Gadovist, and ProHance. A significant five-fold reduction of $T_{1}$ relaxation time was obtained.
\end{abstract}

Keywords: contrast media, magnetic resonance imaging, gadolinium, lung cancer, cell cultures

Due to the fact that lung cancer has a very poor prognosis, new diagnostic techniques to image early stages of lung tumors may improve therapeutic outcomes as the current lung tumor survival rate is very low (1). The diagnosis of lung tumors often requires invasive removal of tissues for histological analyses. From 1972, Magnetic Resonance Imaging (MRI) has been extremely successful in diagnosing disease in soft tissue (2). MRI can be an extremely useful non-invasive clinical tool for monitoring the therapeutic effect of anti-cancer treatments. However, MRI of lung tumors is very difficult due to the low spin density of hydrogen nuclei in the lungs. This situation creates the susceptibility effect of lung tissue-air boundaries (3). Recently, the use of laser hyper-polarized (HP) noble gas isotopes such as ${ }^{3} \mathrm{He}$ and ${ }^{129} \mathrm{Xe}$ has been of increasing interest for use in a variety of MRI applications including imaging lung tissue. Conventional MRI sequences are usually based on the fact that the polarization state is initially in equilibrium and will recover after RF pulsing. Since HP gas is not an equilibrium state, imaging procedures must be adapted accordingly, and the expense of the required laser optical pumping facility limits the potential of HP MRI in clinical medicine applications.
CE-MRI is based on a procedure to shorten spin-lattice relaxation time $\left(\mathrm{T}_{1}\right)$ and thereby increase the repetition rate (TR). A shorter $T_{2}$ can result in lower sensitivity. Contrast agents have found multiple applications in diagnostic medicine because of their ability to improve the quality of contrast. Due to the accumulation of the contrast medium in tissue and the pulse sequence performed, we can obtain two types of images: hyperintensive ( $T_{1}$ dependent images) and hypointensive ( $\mathrm{T}_{2}$ dependent images). In Poland, there are only a few MR research sites and only a fraction of these sites is studying methods in quantitative MRI as in clinical practice, the quantitative approach is not generally utilized. However, medical MRI and experimental MRI are both based on quantitative measurements. The main reasons for this are time constraints and possession of special knowledge for measurements. The use of quantitative measurements is extremely important in achieving a better contrast between healthy and pathological different tissues in clinical diagnosis. The main action of contrast agents is to reduce $T_{1}$ relaxation time in tissue. As a result, tissues that have absorbed the contrast agent give a stronger signal in the images $(4,5)$. On the pharmacy market, gadoliniumbased contrast agents come in two forms: ionic and

\footnotetext{
* Corresponding author: e-mail: dbartusik-aebisher@ur.edu.pl
} 
non-ionic. It should be noted that contrast agents used in CE-MRI are much less likely to cause allergic reactions. In this work, we imaged lung cell culture in vitro with clinical contrast agents to evaluate $\mathrm{T}_{1}$ relaxation time. In this manner, we would like to present results that suggest that CE-MRI can be useful in the imaging of in vitro lung cell culture.

\section{EXPERIMENTAL}

\section{Materials}

The A549 cell line (ATCC ${ }^{\circledR}$ CCL-185 TM) was from the ATCC (American Type Culture Collection $\left(\right.$ ATCC $\left.^{\circledR}\right)$ MANASSAS, VA, USA) and was purchased through LGC (Łomianki, Poland). Culture medium Dulbecco's Modified Eagle's Medium, Dulbecco's Modified Eagle's Medium Nutrient Mixture F-12 Ham Penicillin-StreptomycinNeomycin Solution Stabilized were purchased from Sigma-Aldrich (Sigma Aldrich, MO, USA). Fetal Bovine Serum was purchased from Biochrom, Germany. Accutase Cell Detachment Solution was from Corning (Corning, NY, USA) and tissue culture flasks from ThermoFisher Scientific (ThermoFisher Scientific, MA, USA). Contrast agents such as Omniscan was purchased from General Electric Healthcare (Oslo, Norway), MultiHance was purchased from Bracco Imaging (Bracco Imaging Polska Sp. z o.o. Warsaw, Poland), Gadovist was purchased from Bayer HealthCare Pharmaceuticals (Berlin, Germany).

\section{Cell cultures}

The A549 cell line (ATCC ${ }^{\circledR}$ CCL-185 ${ }^{\mathrm{TM}}$ ) were cultured under standard conditions: temperature $37^{\circ} \mathrm{C}, 5 \% \mathrm{CO}_{2}$ and $95 \%$ humidity. The culture medium consisted of Dulbecco's Modified Eagle's Medium (Sigma-Aldrich, MO, USA), Dulbecco's Modified Eagle's Medium Nutrient Mixture F-12 Ham (Sigma-Aldrich, MO, USA), Fetal Bovine Serum (Biochrom, Germany) and PenicillinStreptomycin-Neomycin Solution Stabilized (Sigma-Aldrich, MO, USA). The culture of lung cancer cells was passaged in 3rd day with the use of Accutase Cell Detachment Solution (Corning, NY, USA) into $70 \mathrm{~mL}$ tissue culture flasks (ThermoFisher Scientific, MA, USA). This study used lung cancer cells A549 prepared in 4 separate samples indicated as Cells 1, Cells 2, Cells 3, and Cells 4. Each sample was centrifuged and the final density was approximately $10^{10}$ cells $/ \mathrm{mL}$. The contrast media used consisted of $50 \mu \mathrm{L}$ Omniscan in $1 \mathrm{~mL}$ water $(25 \mathrm{mmol} / \mathrm{L}), 50 \mu \mathrm{L}$ MultiHance in $1 \mathrm{~mL}$ water $(25 \mathrm{mmol} / \mathrm{L}), 50 \mu \mathrm{L}$ Gadovist in $1 \mathrm{~mL}$ water
$(50 \mathrm{mmol} / \mathrm{L})$ and $50 \mu \mathrm{L}$ ProHance in $1 \mathrm{~mL}$ water $(25$ $\mathrm{mmol} / \mathrm{L}$ ). These are gadolinium-based agents used in clinical diagnostics.

Available pharmaceutical contrast agents are:

Omniscan (Fig. 1), also called Gadodiamidum, is produced by General Electric Healthcare (Oslo, Norway). The active substance of Omniscan is gadodiamide (GdDTPA-BMA) available at a concentration of $287 \mathrm{mg} / \mathrm{mL}(0.5 \mathrm{mmol} / \mathrm{mL})$ and the other ingredients are sodium hydroxide or hydrochloric acid for $\mathrm{pH}$ adjustment.

MultiHance (Fig. 2), also called Dimeglumini gadobenas, is produced by Bracco. The active substance of MultiHance is gadobenic acid, $1 \mathrm{~mL}$ solution for injection contains gadobenic acid at a concentration of $334 \mathrm{mg}(0.5 \mathrm{mmol} / \mathrm{mL})$ in the form of gadobenate dimeglumine $(529 \mathrm{mg} / \mathrm{mL})$.

Gadovist (Fig. 3), also called as Gadobutrolum, is produced by Bayer. The active substance of Gadovist is gadobutrol at a concentration of 529 $\mathrm{mg} / \mathrm{mL}(0.5 \mathrm{mmol} / \mathrm{mL})$, and other ingredients are calculobutrol sodium trometamol and $3.6 \%$ hydrochloric acid in water for injections.

ProHance (Fig. 4), also called Gadoteridolum, comes from Bracco. The active substance is gadoteridol at concentrations of $279.3 \mathrm{mg} / \mathrm{mL}(0.5$ $\mathrm{mmol} / \mathrm{mL}$ ). In addition, ProHance contains Calteridol calcium salt, tromethamine, hydrochloric acid or sodium hydroxide for $\mathrm{pH}$ adjustment, and water for injections.

\section{Magnetic Resonance Imaging}

All MRI scans were performed with an Optima MR360 magnetic resonance spectrometer from General Electric Healthcare (Milwaukee, Wisconsin, USA). The camera was supported by the SV23 software version. Lung cancer cells in samples A-D were placed in an MR tunnel and subjected to a series of measurements to determine relaxation times $T_{1}$ and $T_{2}$. The lung cancer cells in the vials were placed on the FLEX Small transceiver. To perform the measurements, the Fast Spin Echo (FSE) sequence was used with the following parameters: FOV field of view $=10 \times 10 \mathrm{~cm}$; Matrix $=320 \times$ 224; NEX = 2.0; Slice Thickness $=1.0 \mathrm{~mm}$; spacing $=0.5$. TR time varied in the range of $48 \div 15000 \mathrm{~ms}$ (in the following steps: 48, 50, 100, 150, 200, 300, 500, 1000, 1500, 2000, 3000, 5000, 10000, 15000) and TE was $3 \mathrm{~ms}$. To determine $\mathrm{T}_{1}$ relaxation time of cancer cells with the contrast agent, measure- 


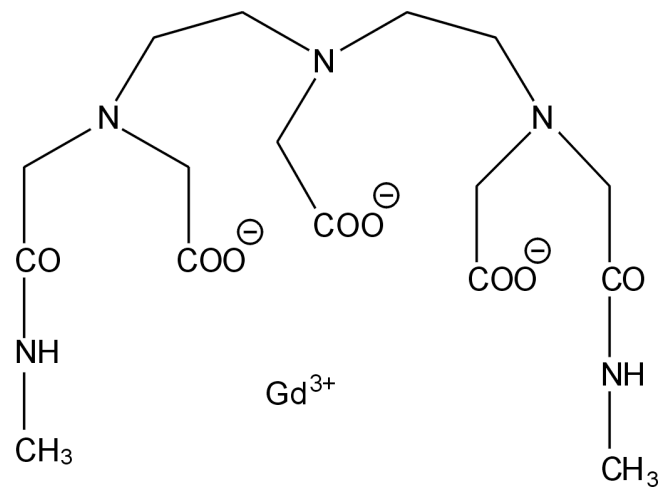

Figure 1. Omniscan.

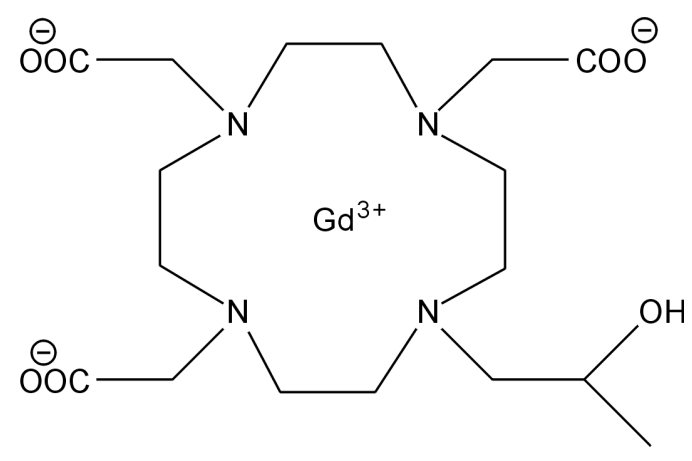

Figure 3. Gadovist.<smiles>CCCCCCCCC(=O)OCC(=O)O</smiles>

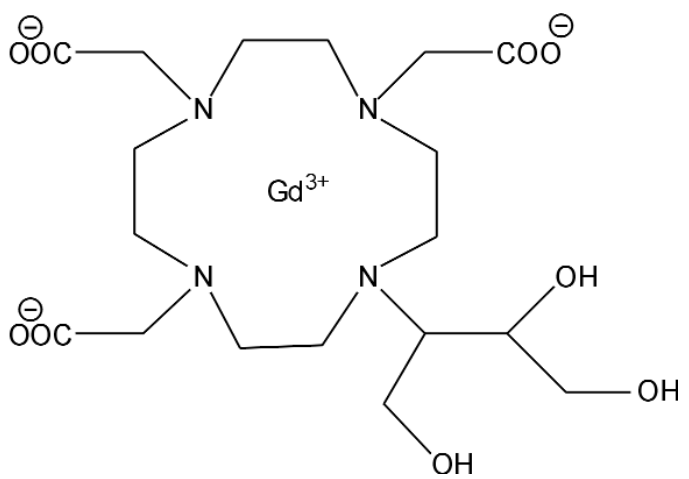

Figure 4. ProHance.

Table 1. Concentration of contrast agents for steps 1-5 in mmol/L.

\begin{tabular}{|c|c|c|c|c|c|}
\hline $\begin{array}{c}\text { Contrast } \\
\text { Agent }\end{array}$ & $\begin{array}{c}\text { Step 1 } \\
(\mathrm{mmol} / \mathrm{L})\end{array}$ & $\begin{array}{c}\text { Step 2 } \\
(\mathrm{mmol} / \mathrm{L})\end{array}$ & $\begin{array}{c}\text { Step 3 } \\
(\mathrm{mmol} / \mathrm{L})\end{array}$ & $\begin{array}{c}\text { Step 4 } \\
(\mathrm{mmol} / \mathrm{L})\end{array}$ & $\begin{array}{c}\text { Step 5 } \\
(\mathrm{mmol} / \mathrm{L})\end{array}$ \\
\hline Omniscan & 25 & 25 & 23.8 & 22.7 & 20 \\
\hline MultiHance & 25 & 25 & 23.8 & 22.7 & 20 \\
\hline Gadovist & 50 & 50 & 47.6 & 45.5 & 40 \\
\hline ProHance & 25 & 25 & 23.8 & 22.7 & 20 \\
\hline
\end{tabular}

ments were performed in 5 contrast-dilution steps for Omnicsan, MultiHance, Gadovist, and ProHance, respectively. All prepared lung cell culture samples were imaged and $T_{1}$ relaxation time was determined before contrast agents were added. The addition of contrast agents to lung cells culture was performed as follow: Step 1- $50 \mu \mathrm{L}$ of the contrast in $1 \mathrm{~mL}$ of $\mathrm{H}_{2} \mathrm{O}$; Step 2- after 24, the measurements of step 1 was repeated; Step 3- $50 \mu \mathrm{L}$ of $\mathrm{H}_{2} \mathrm{O}$ was added to step 2 sample; Step 4- $100 \mu \mathrm{L}$ of $\mathrm{H}_{2} \mathrm{O}$ was added to step 2 sample and Step 5- $250 \mu \mathrm{L}$ of $\mathrm{H}_{2} \mathrm{O}$ was added to step 2 . The contrast agent concentrations for steps $1-5$ are listed in Table 1 in mmol/L.

\section{Statistical analysis}

Results are presented as the mean \pm standard deviation (SD) of six independent experiments.

\section{RESULTS AND DISCUSSION}

The relaxation time of lung cancer cells: cells 1 , cells 2 , cells 3 and cells 4 were $1017 \pm 11 \mathrm{~ms}$, $1485 \pm 14 \mathrm{~ms}, 1092 \pm 11 \mathrm{~ms}$ and $1378 \pm 13 \mathrm{~ms}$, respectively (Fig. 5A). Then, samples cells 1 , cells 2 , cells 3 and cells 4 were treated with $50 \mu \mathrm{L}$ of Omniscan, MultiHance, Gadovist and ProHance in 1 $\mathrm{mL}$ water, respectively (Figure 5B). The samples were measured again after $24 \mathrm{~h}$. In the next step, the same samples were tested with $100 \mu \mathrm{L}$ of $\mathrm{H}_{2} \mathrm{O}$ added (Fig. 5 C).

Step 1: $50 \mu \mathrm{L}$ of the contrast agents Omniscan, MultiHance, Gadovist, and ProHance was dissolved in $1 \mathrm{~mL}$ of $\mathrm{H}_{2} \mathrm{O}$ and added to the cells. $\mathrm{T}_{1}$ relaxation times of pure contrast agents Omniscan, Multi- 

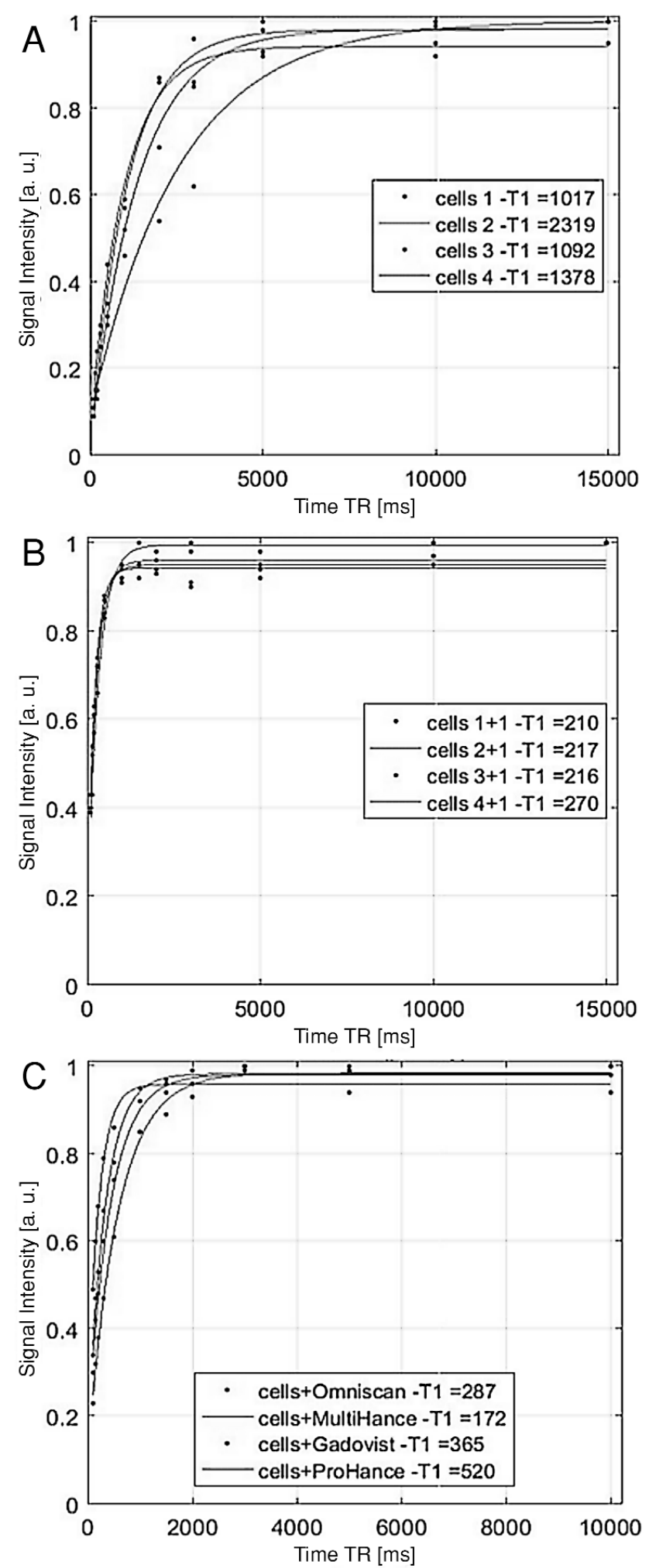

Figure 5A-C. Signal intensity (a.u.) as a function of time (ms) for 5A) Cell cultures 1-4 without contrast agent, 5B) Cell cultures 1-4 treated with $1 \mathrm{~mL}$ of water containing $50 \mu \mathrm{L}$ of Omniscan, MultiHance, Gadovist and ProHance, 5C) Cell cultures 1-4 treated with $1 \mathrm{~mL}$ of water containing $50 \mu \mathrm{L}$ of Omniscan, MultiHance, Gadovist, and ProHance plus $100 \mu \mathrm{L}$ of $\mathrm{H}_{2} \mathrm{O}$ added to each sample. 
Hance, Gadovist and ProHance were $210 \pm 4,217 \pm$ $4,216 \pm 4$ and $270 \pm 5 \mathrm{~ms}$, respectively. The relaxation times show that the maximum discrepancy was between the Omniscan and ProHance contrast agents equal to $60 \pm 2 \mathrm{~ms}$. The presented data are mean values \pm standard deviation of six independent experiments.

Step 2: The measurement was repeated after $24 \mathrm{~h}$. For the cells treated with Omniscan contrast agent, the difference is a $77 \pm 5 \mathrm{~ms}$ increase, for Gadovist the relaxation time $T_{1}$ increased by $55 \pm 5 \mathrm{~ms}$, and for ProHance it increased by $220 \pm 5 \mathrm{~ms}$. In the case of MultiHance, the result dropped by $45 \mathrm{~ms}$, when compared to step 1 .

Step 3: A $50 \mu \mathrm{L}$ of water was added to each sample and the $T_{1}$ relaxation time was again determined from six independent experiments.

For three contrast agents, a decrease in the $T_{1}$ time was observed. In the case of Omniscan, the value of $\mathrm{T}_{1}$ decreased by another $25 \pm 5 \mathrm{~ms}$, for Gadovist $74 \pm 5 \mathrm{~ms}$, for ProHance it decreased by $245 \pm 5 \mathrm{~ms}$. In the case of MultiHance, the value increased by $18 \mathrm{~ms}$.

Step 4: A further $100 \mu \mathrm{L}$ of water was added to the same samples. In the case of Omniscan, the observed difference in $\mathrm{T}_{1}$ relaxation time was a 17 $\mathrm{ms}$ increase. However, in the case of the other three contrast agents, the values increased for MultiHance by $10 \pm 5 \mathrm{~ms}$, for Gadovist by $101 \pm 5 \mathrm{~ms}$, and for ProHance by $121 \pm 5 \mathrm{~ms}$.

Step 5: A $250 \mu \mathrm{L}$ of water was added, an increase in the $T_{1}$ relaxation time value was observed for all four contrast agents. For Omniscan it increased by $56 \pm 5 \mathrm{~ms}$, for MultiHance by $32 \pm 5 \mathrm{~ms}$, for Gadovist by $107 \pm 5 \mathrm{~ms}$, and for ProHance the highest increase of $214 \pm 5 \mathrm{~ms}$ was observed.

Figure 6 below shows the changes in $T_{1}$ relaxation times for the prepared samples after 5 steps included in Table 2. The various changes in $T_{1}$ measurements are presented in Figure 6.

In a review by Dietrich et al., $\mathrm{T}_{1}$ relaxation time in the lung parenchyma in healthy people in the 1.5 Tesla field was described. It was determined that the average $T_{1}$ relaxation time for healthy lung tissue at 1.5 Tesla was approximately $1200 \mathrm{~ms}$ with a standard deviation of $150 \mathrm{~ms}$ (6). Paramagnetic contrast substances are well-soluble in water, in addition, they have the ability to completely absorb from the digestive system and circulation into the intercellular spaces. In addition, no drug interactions have been reported so far. Iron-based shading agents are most often used to determine focal lesions in the liver and other gastrointestinal pathologies. For liver pathology, manganese-based contrasts are also used, but unlike iron-based contrasts, the goal is to make healthy tissues visible. In contrast, agents based on

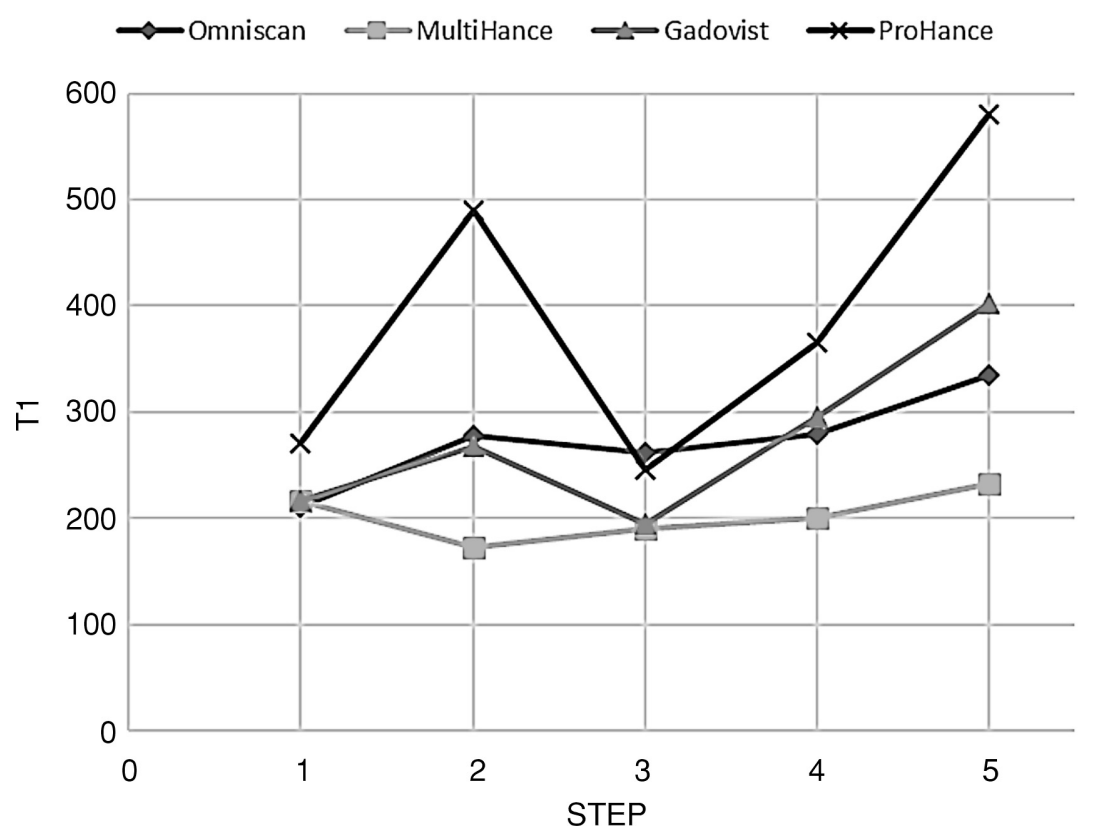

Figure 6. $T_{1}$ relaxation time corresponding to steps 1-6. 
dysprosium are used in imaging of heart and brain diseases. Generally, positive contrast agents in medical diagnostics are used to diagnose diseases of the central nervous system, heart, digestive system, with particular emphasis on the liver and kidneys as well as the musculoskeletal system. In addition, the whole group of positive contrast agents can be divided into extracellular contrast agents, mainly used for angiographic studies (showing stenosis or aneurysms) and intracellular, which are absorbed into the cells by binding to proteins. Intracellular shaders are invaluable for imaging small vessels. They are most often used in imaging of tumors, due to the fact that with their use, the doctor can realistically assess the size of the tumor and its location. In addition, they are able to visualize all kinds of inflammatory changes and ischemia. The second group of shading agents are negative contrast agents that reduce the intensity of the signal in the tissue (reduce the $\mathrm{T}_{2}$ relaxation time). Unlike positive contrast agents, the MR image is darker. One of the most commonly used agents is magnetite, it is administered orally or intravenously, usually for liver tests. Numerous scientific studies present the use of contrast agents in scientific research using methods of determining relaxation times. The longitudinal and transverse relaxation times $T_{1}$ and $T_{2}$ are the times after which they reach a certain defined value. For $\mathrm{T}_{1}$ it will be about $63 \%$ of the total magnetization value, while for $\mathrm{T}_{2}$ it will be $37 \%$. By browsing PubMed's scientific database, we can find papers describing the use of contrast media for research on cell cultures (7-10). Table 3 presents MRI study with contrast agents used in clinical diagnostics. Contrast agents used in MRI have found wide application due to the properties of improving

Table 2. Results of $T_{1}$ relaxation times for lung cancer cell cultures cells 1-4. The presented data are mean values \pm standard deviation of six independent experiments.

\begin{tabular}{|c|c|c|c|c|}
\hline & Omniscan & MultiHance & Gadovist & ProHance \\
\cline { 2 - 5 } & cells 1 & cells 2 & cells 3 & cells 4 \\
\cline { 2 - 4 } & $\mathrm{T}_{1}(\mathrm{~ms})$ & $\mathrm{T}_{1}(\mathrm{~ms})$ & $\mathrm{T}_{1}(\mathrm{~ms})$ & $\mathrm{T}_{1}(\mathrm{~ms})$ \\
\cline { 2 - 5 } & $1017 \pm 7$ & $1485 \pm 9$ & $1092 \pm 6$ & $1378 \pm 7$ \\
\hline Step 1 & $210 \pm 4$ & $217 \pm 4$ & $216 \pm 4$ & $270 \pm 5$ \\
\hline Step 2 & $287 \pm 1$ & $172 \pm 3$ & $268 \pm 2$ & $490 \pm 2$ \\
\hline Step 3 & $262 \pm 2$ & $190 \pm 2$ & $194 \pm 3$ & $245 \pm 3$ \\
\hline Step 4 & $279 \pm 2$ & $200 \pm 2$ & $295 \pm 2$ & $366 \pm 1$ \\
\hline Step 5 & $335 \pm 2$ & $232 \pm 2$ & $402 \pm 1$ & $580 \pm 2$ \\
\hline
\end{tabular}

Table 3. A review of CE-MRI studies.

\begin{tabular}{|c|c|c|c|}
\hline Authors/year & Ref & Experiment & Result \\
\hline Sobhani T. et al. 2019 & $(11)$ & $\begin{array}{l}\text { Manganese-zinc ferrite nanoparticles } \\
\text { and L929 cell lines }\end{array}$ & $\begin{array}{l}\text { Longitudinal relaxivity } \\
85.5 \mathrm{mM}^{-1} \mathrm{~s}^{-1}\end{array}$ \\
\hline Haedicke I.E. et al. 2019 & (12) & Manganese porphyrin contrast agent & $\begin{array}{c}\text { Four-fold lower } \mathrm{T}_{1} \text { relaxation } \\
\text { time. }\end{array}$ \\
\hline Huang Q. et al. 2019 & (13) & $\begin{array}{l}\text { Iron-doped carbon quantum dots for } \\
\qquad 3.92 \mathrm{mM}^{-1} \cdot \mathrm{s}^{-1}\end{array}$ & Longitudinal relaxivity \\
\hline Li X. et al. 2019 & (14) & $\begin{array}{c}\text { Silane-polyethylene glycol modified } \\
\text { HS-Fe (HS-Fe-PEG) NPs }\end{array}$ & $\mathrm{T}_{2}$-weighted $\mathrm{MR}$ imaging \\
\hline Wang J. et al. 2019 & $(15)$ & Glucose and levofloxacin & $\begin{array}{l}\text { Longitudinal relaxivity } \\
5.79 \mathrm{mM}^{-1} \cdot \mathrm{s}^{-1}\end{array}$ \\
\hline Yang Y. et al. 2014 & $(16)$ & Gd-DOTA & $\begin{array}{l}\text { Longitudinal relaxivity } \\
7.55 \mathrm{mM}-1 \mathrm{~s}^{-1}\end{array}$ \\
\hline Yuan Z. et al. 2007 & $(17)$ & Gd-DTPA & Gd-DTPA enhanced MRI \\
\hline Crisci R. et al. 1997 & (18) & Gd-DTPA & Gd-DTPA enhanced MRI. \\
\hline Carney C.E. et al. 2015 & (19) & Gd-DTPA & Gd-DTPA enhanced MRI \\
\hline
\end{tabular}



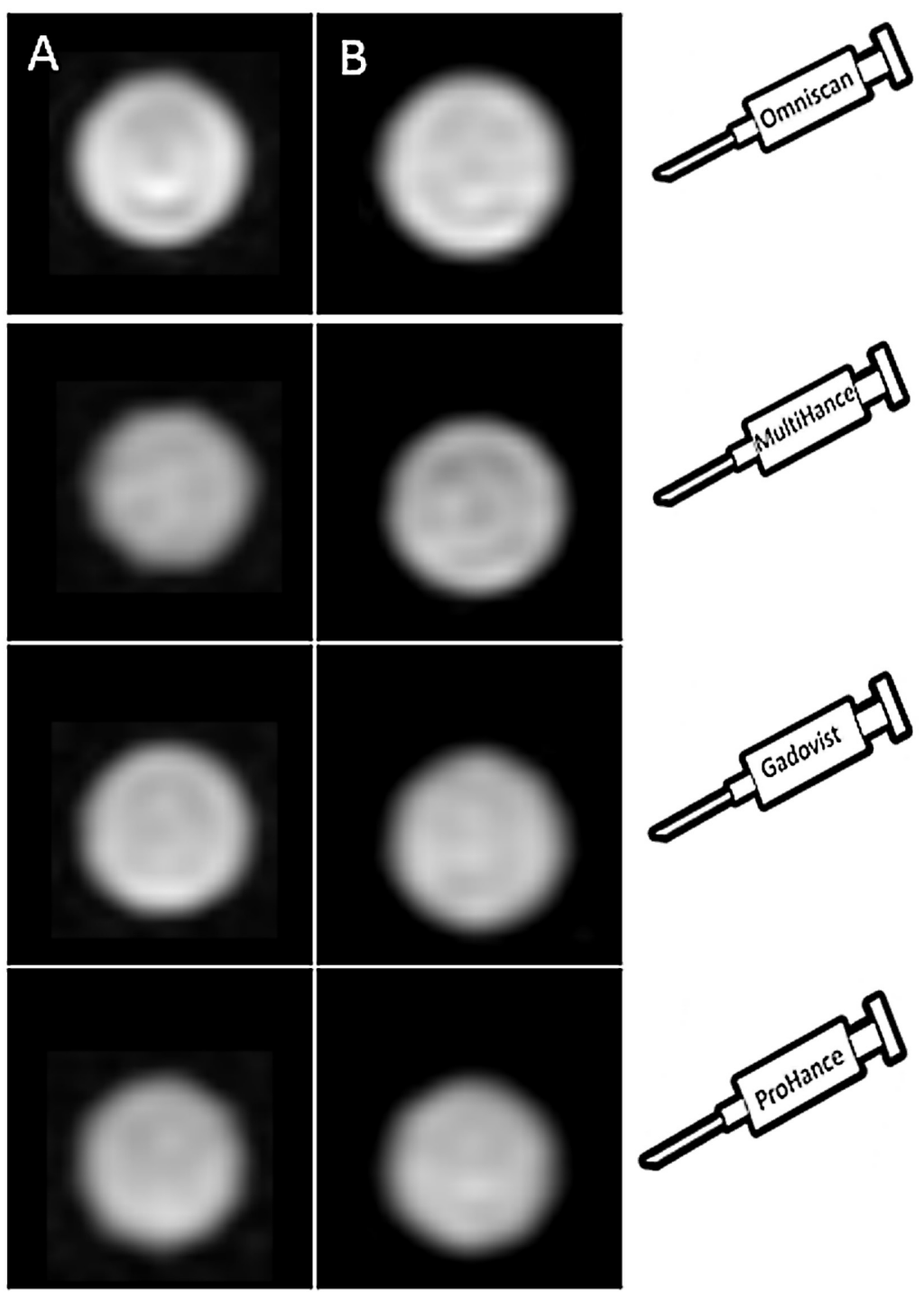

Figure 7. MRI images of lung cancer cell culture A) before treatment and B) after treatment with contrast agents Omniscan, MultiHance, Gadovist, and ProHance.

the quality of diagnostic images. In diagnostics, it is important to obtain a satisfactory contrast. One of the most commonly used contrast agents in clinical practice is gadolinium, which is based on one of the metals from the so-called "rare earth" group, from the lanthanide group. These are metals with paramagnetic properties, they have magnetic properties in the external magnetic field. The main principle of gadolinium is to reduce the $\mathrm{T}_{1}$ relaxation time.

Currently, new and easier ways of identifying drug forms are being sought. In our view, MRI techniques are needed to provide more efficient earlystage diagnosis, predict disease course, and develop a more effective therapy. We propose a qualitative and quantitative study of important agents such as contrast agents (Fig. 7) to increase contrast agent specificity. We want to develop MRI methodology to test new contrast agents before they are used in the clinic. However, we want to establish our technique by using available and known contrast agents. We hope that our pre-clinical methodology will be helpful for clinical studies and pharmaceutical practices. One of the initial assumptions of this project is that we will use MRI measurements to model drug formulations. These proposed measurements will allow us to assess the physic-chemical properties of already existing drugs for the benefit of improving medicine. Qualitative and quantitative analysis of 
drugs using MRI will enable to study molecular properties.

The interdisciplinary aspect of this project will allow for simultaneous spectroscopic and imaging studies. At each stage, optimization of conditions and parameters of imaging, spectroscopic and analytical measurements will be performed. Estimation of change in drug form and stability of the drug substance can be analyzed by MRI as a function of $\mathrm{pH}$, temperature and light exposure. One of the goals of this project was to use the 1.5 Tesla MRI scanner for molecular research on relaxation measurements. We hope that clinicians working in the field of in vitro contrast-enhanced MRI for lung cancer diagnostics will be able to use the generated data to further improve diagnostic methods. In addition, we hope that this study of contrast agents in cell culture will inspire other researchers to develop MRI methodology for future clinic studies.

\section{CONCLUSIONS}

With MRI, we are able to provide non-invasive ways to visualize molecular events during controlled-release dosage. Using MRI, we also have a tool that is helpful in understanding the processes that occur in drug metabolism. This may have a significant impact on the development of a new generation of pharmaceuticals such as contrast agents.

\section{Acknowledgments}

Dorota Bartusik-Aebisher acknowledges support from the National Center of Science NCN (New drug delivery systems-MRI study, Grant OPUS-13 number 2017/25/B/ST4/02481).

\section{Conflicts of interest}

The authors declare no conflict of interest.

\section{REFERENCES}

1. Yang P.: Methods Mol. Biol. 471, 469, (2009).

2. Lauterbur P.C.: Nature 242, 190, (1973).

3. Tycko R., Reimer J.A.: J. Phys. Chem. 100, 13240 (1996).

4. Brunner E.: Concepts Magn. Reson. 11, 313 (1999).

5. Albert M.S., Cates G.D., Driehuys B., Happer W., Saam B., et al.: Nature 370, 199 (1994).

6. Dietrich O., Gaass T., Reiser M.F.: Eur. J. Radiol. 86, 252 (2017).

7. Adriaensen H., Musse M., Quellec S., Vignaud A., Cambert M., et al.: Magn. Reson. Imaging 31, 1677, (2013).

8. Akber S.F.: Physiol. Chem. Phys. Med. NMR 40, 1 (2008).

9. Alamidi D.F., Kindvall S.S., Hubbard Cristinacce P.L., McGrath D.M., Young S.S., et al.: PLoS One, 11, e0149760 (2016).

10. Arbab A.S., Yocum G.T., Kalish H., Jordan E.K., Anderson S.A., et al.: Blood 104: 1217 (2004).

11. Sobhani T., Shahbazi-Gahrouei D., Rostami M., Zahraei M., Farzadniya A.: J. Med. Signals. Sens. 9, 245 (2019).

12. Haedicke I.E., Loai S., Cheng H.M.: Contrast Media Mol. Imaging ID 3475786, 11 pages (2019).

13. Huang Q., Liu Y., Zheng L., Wu L., Zhou Z., et al.: Mikrochim. Acta 186, 492 (2019).

14. Li X., Xia S., Zhou W., Ji R., Zhan W.: Int. J. Nanomedicine 14, 2397 (2019).

15. Wang J., Hu X., Ding H., Huang X., Xu M., et al.: ACS Appl. Mater. Interfaces 11, 18203 (2019).

16. Yang Y., Zhou J., Yu K.: Amino Acids 46, 449 (2014).

17. Yuan Z., Liu S.Y., Xiao X.S., Zhong G.R., Jiang Q.J.: Zhonghua Yi Xue Za Zhi 87, 673 (2007).

18. Crisci R., Di Cesare E., Lupattelli L., Coloni G.F.: Eur. J. Cardiothorac. Surg. 11, 214 (1997).

19. Carney C.E., MacRenaris K.W., Meade T.J.: J. Biol. Inorg. Chem. 20, 971 (2015).

(C) 2020 by Polish Pharmaceutical Society. This is an open-access article under the CC BY NC license (c) (1) (\$) (http://creativecommons.org/licenses/by-nc/4.0/). 